Article

\title{
Isolates of the Nematophagous Fungus Pochonia chlamydosporia Are Endophytic in Banana Roots and Promote Plant Growth
}

\author{
Cristina Mingot-Ureta ${ }^{1, * \mathbb{D}}$, Federico Lopez-Moya ${ }^{1} \mathbb{C}$ and Luis Vicente Lopez-Llorca ${ }^{1,2}$ \\ 1 Laboratory of Plant Pathology, Department of Marine Sciences and Applied Biology, University of Alicante, \\ 03080 Alicante, Spain; federico.lopez@ua.es (F.L.-M.); lv.lopez@ua.es (L.V.L.-L.) \\ 2 Multidisciplinary Institute for Environmental Studies (MIES) Ramon Margalef, University of Alicante, \\ 03080 Alicante, Spain \\ * Correspondence: cristina.mingot@ua.es
}

Received: 16 July 2020; Accepted: 30 August 2020; Published: 1 September 2020

\begin{abstract}
The biocontrol fungus Pochonia chlamydosporia colonizes banana roots endophytically. Root hairs and root surface were colonized by a stable GFP (green fluorescent protein) transformant of the fungus. Hyphal penetration in root cells was also observed. Spores of P. chlamydosporia 123, significantly increase root and leaf length and weight in banana plantlets (Musa acuminata cv. 'Dwarf Cavendish') in growth chamber experiments 30 days post-inoculation. In greenhouse 8-L pot experiments, P. chlamydosporia 123 spore inoculation significantly increases root, corm and leaf length, and leaf weight in banana plants (75 days post-inoculation). Spore inoculation of P. chlamydosporia strains from diverse origin (Pc21, Pc123, Pc399, and Pccat), significantly increase root, corm and leaf length and weight in banana plantlets. Pc21 from Italy was the best colonizer of banana roots. Consequently, this strain significantly increases banana root and leaf length most. Root colonization by P. chlamydosporia was also detected using cultural techniques and qPCR.
\end{abstract}

Keywords: banana; root colonization; Pochonia chlamydosporia;Musa acuminata; growth promotion; endophyte

\section{Introduction}

Banana (Musa acuminata) is a monocotyledonous plant of Musaceae family. It is a large herbaceous plant, without a true trunk, instead foliar pods that form a pseudostem [1]. Banana fruit is the fourth most important crop in the world [2]. Crop yield is conditioned by biotic interactions (positive or negative) which occur in the rhizosphere [3-5]. Important pests and diseases such as black weevil (Cosmopolites sordidus), plant pathogenic fungi (Fusarium oxysporum f. sp. cubense), and plant-parasitic nematodes [6-9] can affect banana plants. Nematodes are soil-borne pathogens that cause significant economic losses in banana plantations [10,11]. Biological control agents can be used for biomanagement of plant-parasitic nematodes such as Meloidogyne spp. [12,13]. Pochonia chlamydosporia (Pc), a fungus parasitic on nematode eggs [14-16], is a good example. This fungus has been studied extensively for sustainable management of nematodes affecting crops of economic importance such as cucumber [17]. Pc can be influenced by root exudates $[18,19]$ and lives also as a saprophyte in the soil. However Pc is a true endophyte able to prime plant root cells [20,21]. Colonizing roots Pc obtains nutrients and protection from the host plant [22]. Pc can colonize a large variety of crops such as tomato, lettuce, and wheat and promote their growth. [23-25]. This is due to production of secondary metabolites such as cytokinins, gibberellic acid, ethylene, and other metabolites [20,21,26-28] during plant colonization by Pc. Pc can also induce indole-3-acetic acid (IAA) biosynthesis related with root growth promotion, extension, and cellular division or enhancing nutrient uptake promoting the plant growth $[25,29]$. These properties make Pc a good tool for banana plant biomanagement $[20,30]$. 
We hypothesize that Pc spores spread better than mycelium in soil, so they best promote plant growth. Growth promotion fades with time due to slow root colonization by Pc. Therefore, Pc re-inoculation is required to keep plant growth promotion in long-term experiments. Genetic variability of Pc isolates from different origin may also influence their plant growth promotion capabilities.

In this work we inoculate spores or mycelium of the endophytic fungus Pc in roots of Musa plantlets. We then analyze the effect of Pc on root colonization and growth promotion. The best inoculation method is then used in long-term experiments to check its efficiency in plant growth promotion. Besides, we determine the effect of genetic variation of Pc strains in plant growth promotion and root colonization.

\section{Materials and Methods}

\subsection{Plants and Fungi}

In vitro 30-day-old banana plantlets (M. acuminata cv. 'Dwarf Cavendish' AAA) were obtained from Cultesa (Santa Cruz de Tenerife, Canary Islands, Spain). Before experiments, plantlets were acclimatized in a growth chamber (SANYO MLR-351H) for 5-10 days, at $24{ }^{\circ} \mathrm{C}, 60 \%$ relative humidity, and $16 \mathrm{~h} / 8 \mathrm{~h}$ light/darkness photoperiod.

Pc21 (Italy), Pc123 (Spain), Pc399 (China), and Pccat (Cuba) strains from the nematophagous fungus P. chlamydosporia ( $\mathrm{Pc}$ ) were obtained from the Collection of the Phytopathology Laboratory (University of Alicante, Spain). Pc21 was isolated in Metaponto (Italy) from Meloidogyne spp. in kiwi trees [30] and was a kind gift from Dr. A. Ciancio (CNR, Bari, Italy). Pc123 was isolated from Heterodera avenae eggs in southwest Spain [31]. Pc399 was obtained in China by late Professor Brian Kerry (Rothamsted Research, Harpenden, UK), who kindly sent us the strain for research purposes. Pccat was isolated from Meloidogyne spp. infected eggs in Cuba [27] and was a kind gift from Dr. L. Hidalgo (CENSA, Cuba).

\subsection{Growth Chamber Experiments}

Plantlets were grown individually in 200-mL polystyrene cups with sterilized Terraplant 2 peat (Compo Expert, Castellón, Spain). The experiment included three treatments with Pc123 and control. Treatment 1 consisted of plantlets inoculated with eight 5-mm diameter cores from the edge of a 21-day-old Pc123 colony on CMA. In Treatment 2, plantlets had roots placed on Pc123 colonies for 7 days in Magenta boxes (GA-7, Sigma, Darmstadt, Germany) with CMA. These plantlets were then transferred individually to polystyrene cups with peat. In Treatment 3 , plantlets were inoculated with $1 \times 10^{4}$ Pc123 conidia and chlamydospores/gram of substrate. Controls were polystyrene cups with sterilized peat and a banana plantlet only. Plantlets were irrigated every $48 \mathrm{~h}$ with sterilized 1/10 Gamborg's salt solution (Basal Medium Minimal Organic, Sigma). Control and treated plantlets were grown in a growth chamber as described (see Section 2.1). Thirty days after planting, root, corm, and leaf weight and length per plant were assessed. The number of leaves per plant was also recorded. Root colonization by Pc was estimated using culturing techniques at 10, 20, and 30 days post inoculation (dpi) (see Section 2.5). This experiment was repeated three times with 10 plantlets per treatment in each replicate.

To visualize Pc development in roots, banana plantlets were inoculated in Magenta boxes with a Pc 123-GFP (green fluorescent protein) transformant strain [32]. Seven days after inoculation, roots were sampled. Root fragments were then excited with a $488 \mathrm{~nm}$ laser, and GFP fluorescence monitored at 505-530 nm with a Laser Confocal Microscope (Leica TCS-SP2).

\subsection{Greenhouse Experiments}

Thirty plantlets were either inoculated with $5 \times 10^{4}$ Pc123 conidia and chlamydospores/gram of substrate, or not (controls). Plantlets were grown in polystyrene cups, for 30 days as above (see Section 2.2). Five plantlets per treatment were then destructively sampled to assess root colonization by Pc using conventional PCR and qPCR techniques (see Section 2.5). Twenty plants per treatment were then transplanted to 8 -L pots and grown in the greenhouse, at $24{ }^{\circ} \mathrm{C}$ and $60 \%$ relative humidity. Plants either 
received a single (initial) inoculation with $5 \times 10^{4}$ Pc123 conidia and chlamydospores/gram of substrate (Treatment 1), or they were inoculated monthly (three times) with this same inoculum (Treatment 2). Control plants were left uninoculated. Plants were irrigated daily with $100 \mathrm{~mL}$ tap water and were grown for 75 days. Root colonization by Pc was estimated using culturing and PCR techniques (see Section 2.5). This experiment was repeated twice with 20 plants per treatment in each replicate.

\subsection{Pc Strain Variability and Banana Plant Growth Promotion Experiments}

We used Pc21, Pc123, Pc399, and Pccat in banana plantlets as described above (see Section 2.2). The experiment design and conditions were the same as above (see Section 2.1). Treatments consisted of a single initial inoculation of $5 \times 10^{4}$ conidia and chlamydospores/gram of substrate from a given Pc strain per treatment. Thirty-day-old plantlets were scored as above (see Section 2.2). Pc root colonization was also determined using culturing and PCR techniques (see Section 2.5).

\subsection{Root Colonization}

Ten root systems per treatment from plants of either growth chamber or greenhouse experiments were sampled to evaluate root colonization by Pc. Five root systems were used for total root colonization and the rest for endophytic colonization estimations. For total root colonization, roots were rinsed in sterile distilled water three times for $1 \mathrm{~min}$ each. For endophytic colonization, a preliminary $1 \mathrm{~min}$ wash in $1 \%$ sodium hypochlorite was performed. From each root system, $121-\mathrm{cm}$ pieces were randomly sampled axenically. Root samples were then plated on a growth restricting medium [33]. Petri plates with root fragments were incubated for 20 days at $24{ }^{\circ} \mathrm{C}$ in darkness and observed in an optical microscope.

Alternatively, root fragments were also employed to measure root colonization by Pc with PCR using specific primers (Table 1) [34]. An improved cetyl-trimethyl-ammonium bromide (CTAB) extraction method was used for isolating genomic DNA from lyophilized samples [35,36]. PCR was performed using 100 ng DNA mixed with Routine Polymerase $2 X$ (Thermo Fisher) and with each primer at $0.5 \mu \mathrm{M}$. Negative controls contained sterile water only, and positive ones contained $100 \mathrm{ng} / \mu \mathrm{L}$ of Pc123 DNA extracted from axenic cultures. DNA amplification was carried out in PTC-100 Peltier Thermal Cycler. PCR products were run in $1.5 \%$ agarose gel electrophoresis stained with GelRed (Biotium, Hayward, CA, USA).

Table 1. Primers used to detect/quantify the fungus Pochonia chlamydosporia in banana plant roots.

\begin{tabular}{|c|c|c|c|c|}
\hline Name & Sequence $\left(5^{\prime} \rightarrow 3^{\prime}\right)$ & Target & Accession Number & Amplicon Size (pb) \\
\hline VCP1-1F & CGCTGGCTCTCTCACTAAGG & \multirow{2}{*}{$\begin{array}{c}\text { P. chlamydosporia } \\
\text { vcp } 1\end{array}$} & \multirow{2}{*}{ AJ427460 } & \multirow{2}{*}{281} \\
\hline VCP1-2R & TGCCAGTGTCAAGGACGTAG & & & \\
\hline
\end{tabular}

Quantitative PCR (qPCR) was performed in triplicate using a 96-well plate (Roche Diagnostics, Penzberg, Germany) in a Thermal Cycling StepOnePlus (Applied Biosystems, Foster City, CA, USA). Root DNA extracts (10 ng) from each growth chamber treatment were mixed with FastStart Universal SYBR Green Master (Roche, Barcelona, Spain) and with each primer at $0.5 \mu \mathrm{M}$. Negative controls contained sterile water. Standard curves were produced by plotting the average cycle threshold $(\mathrm{Ct})$ values against the log DNA concentration, and amplification efficiencies were calculated from the slope of Ct plotted against log DNA concentration [34,37].

\subsection{Statistical Analysis}

The normality of the data was verified by the Shapiro-Wilk test, and the Levene test was used to study the homogeneity of the variance between the groups. Data that followed a normal distribution were compared using a one-way ANOVA. Non-normal data were compared using Kruskal-Wallis test (K-W). Wilcoxon test was used for multiple tests for pairwise comparisons. In all cases, the level of significance considered was 95\%. All analyses were performed using GraphPad Prism version 8 for Windows (GraphPad Software Inc., San Diego, CA, USA). 


\section{Results}

\subsection{Effect of Pc Inoculation on Plant Growth}

P. chlamydosporia (Pc123) conidia and chlamydospores significantly promoted root, corm, and leaf weight, and also root and leaf length of banana plantlets (Figure 1a,b). Total weight and length of the plants treated with conidia and chlamydospores were 1.8 and 1.4 times greater than the control plants (uninoculated). Number of leaves per plant displayed no differences among treatments (Figure S1). Pc123 can colonize endophytically banana plant roots using both, mycelium, and spores as inoculum in plantlets 10-20-30 dpi (Figure 1c). Root colonization by Pc123 can be detected from 10 dpi onwards using all treatments. We also detected Pc123 GFP transformant in the rhizoplane and root cells of $M$. acuminata 7 dpi (Figure 1d,e). Roots inoculated with conidia and chlamydospores show 30 dpi higher colonization by Pc123 than other treatments evaluated. Therefore, conidia and chlamydospore were used as the inoculum for further experiments.
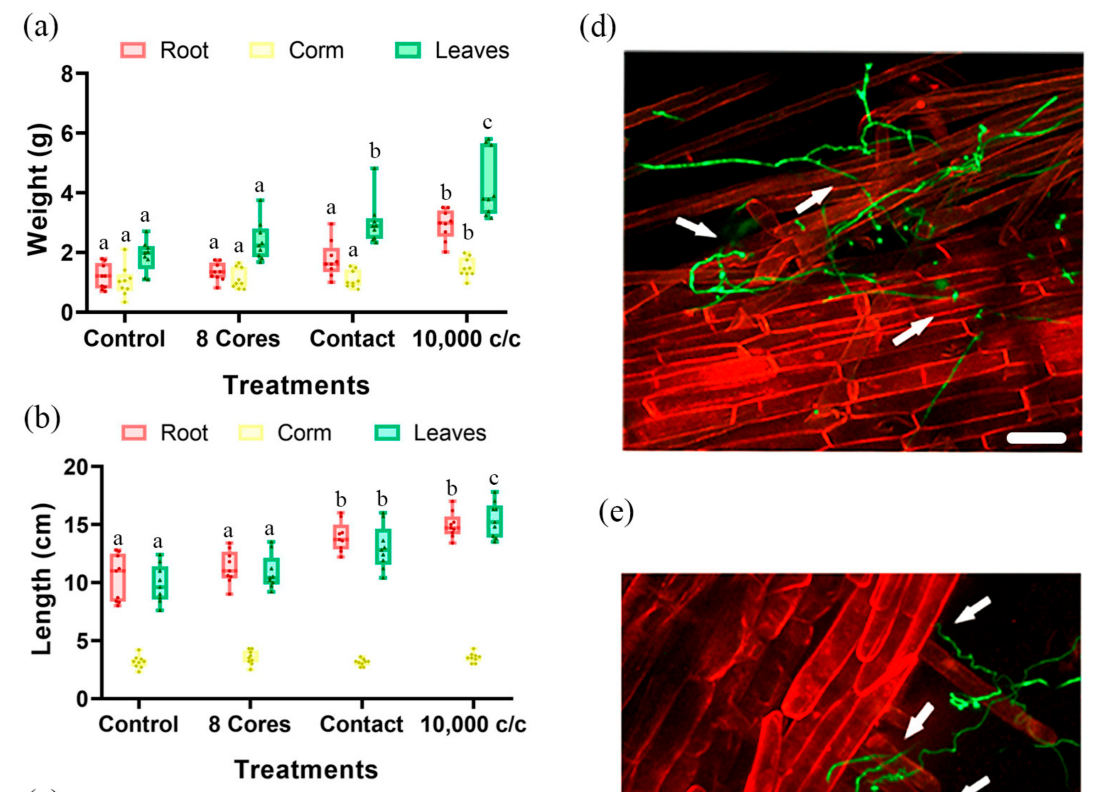

(e)
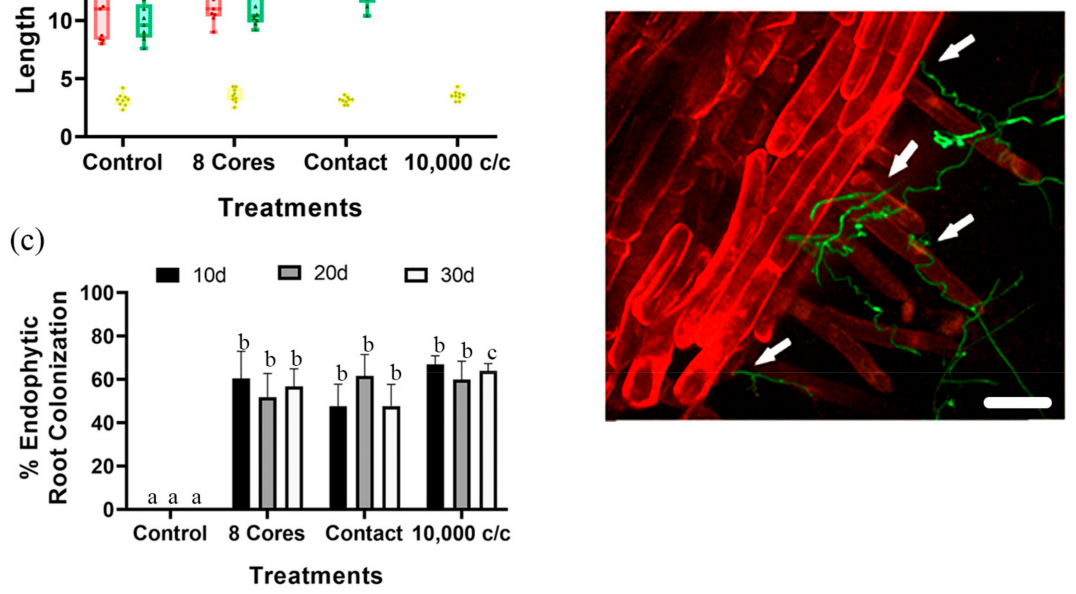

Figure 1. Effect of P. chlamydosporia 123 on banana plantlets. Treatments: eight cores from the edge of 21-day-old P. chlamydosporia (Pc) colony; contact of banana plantlet in Magenta Box with Pc for 5 days; 10,000 c/c spore suspension of Pc; control, uninoculated plantlets. (a) Maximum root, corm, and leaf weight. (b) Fresh root, corm, and leaf length. (c) Endophytic root colonization by Pc123. In the parameters analyzed individually, treatments with different letters indicate significant differences ( $p$-value $<\alpha=$ 0.05), treatments without letters indicate there are no significant differences. (d) Root hairs colonization; (e) rhizoplane colonization of Musa acuminata by Pc123 GFP modified strain. Arrows: indicate possible hyphal penetration points in the root. White bar $=75 \mu \mathrm{m}$.

\subsection{Pc Promotes the Growth of Banana Plants in the Greenhouse}

Pc123 significantly increases leaf weight up to 1.22 times of banana plants in all treatments (Figure 2a). Pc123 also increases root, pseudostem, and leaf length (Figure 2b) between 1.1 and 1.22 
times of banana plants under greenhouse conditions. Differences in the number of leaves per plant were not found (Figure S2). After 30 days we checked that Pc was well established in banana plant roots. Root colonization was verified by PCR (Figure 2c) and qPCR (Figure 2d). qPCR standard curve shows a $\mathrm{R}^{2}$ higher than 0.89 (Figure S3). Molecular quantification of Pc123 in banana root revealed more Pc123 (approx. 3-fold) in total vs. endophytic colonization (Figure 2c). Root colonization by Pc in older banana plants (105-day-old) was estimated by culturing and PCR (Figure 2e,f). Pc123 can persist endophytically in banana roots up to $75 \mathrm{dpi}$ (Figure 2e). Root colonization by Pc123 increases with repeated applications of the fungus.

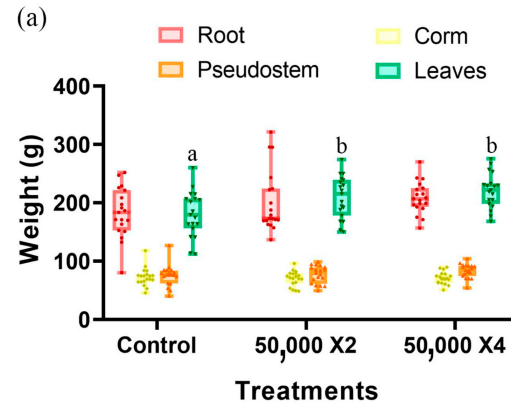

(c)

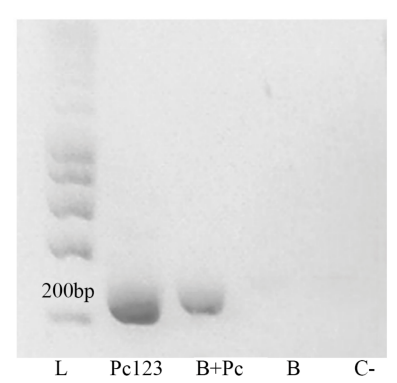

(e)

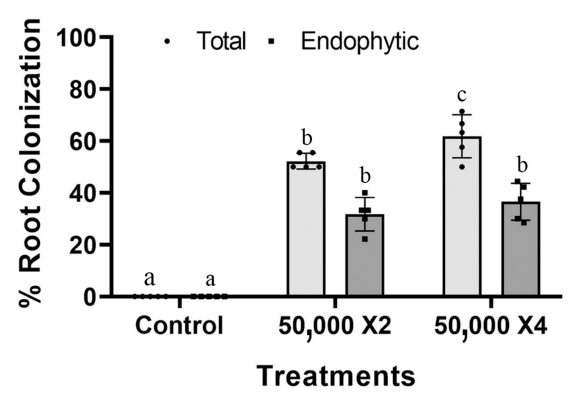

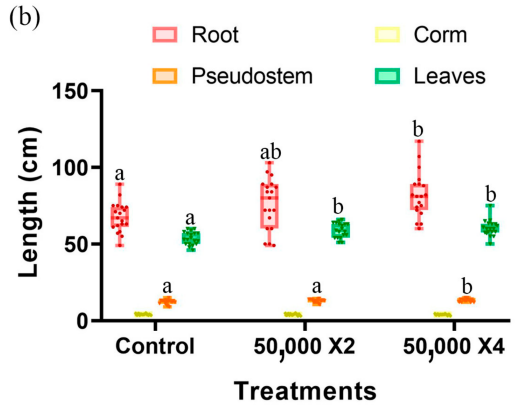

(d)

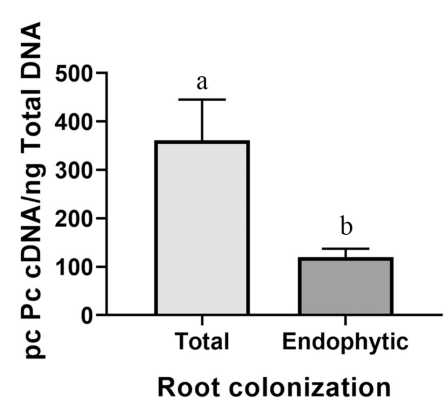

(f)

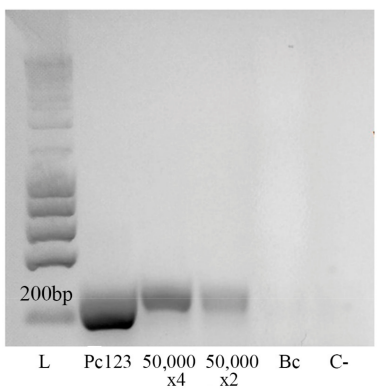

Figure 2. Effect of $P$. chlamydosporia 123 on the growth of banana plants. Treatments: $50,000 \times 2$, two spore inoculation; 50,000 $\times 4$, four spore inoculation; control, uninoculated plants. (a) Maximum root, corm, pseudostem, and leaf weight. (b) Fresh root, corm, pseudostem, and leaf length. In the parameters analyzed individually, treatments with different letters indicate significant differences ( $p$-value $<\alpha=$ $0.05)$, treatments without letters indicate there are no significant differences. (c) Molecular detection of M. acuminata root colonization by Pc123, in 30-day-old plants. (d) Quantification by qPCR of Pc123 colonization of banana plant roots in 30-day-old plants. (e) Total and endophytic colonization of $M$. acuminata root colonization by Pc123 in 105-day-old plants. (f) Molecular detection of M. acuminata root colonization by Pc123 in 105-day-old plants. PCR of the P. chlamydosporia vpc1 gene. Abbreviations: M, ladder; Pc, DNA extracted from the mycelium of P. chlamydosporia; B + Pc, DNA extracted from 30-day-old roots of the plant inoculated by Pc123; B, DNA extracted from the root of a 30-day-old uninoculated banana plant; 50,000 $\times 4$ DNA extracted from four spore inoculation 105-day-old plants; $50,000 \times 2$ DNA extracted from two spore inoculation 105-day-old plants; Bc, DNA extracted from the root of a 105-day-old banana control plant without Pc inoculation; C-, negative control without DNA. 


\subsection{Pc Strains Vary in Their Plant Growth Promotion Ability}

All Pc strains tested caused a significant increase in weight and length in banana plantlets. In Figure $3 a, b$ Pc21 was the most banana plant growth promoting strain. Banana plantlets inoculated with Pc123, Pc399, and Pccat also showed growth promotion. Differences in the number of leaves per plant were not found (Figure S4). Pc21 was the largest colonizer of banana roots (total colonization) (Figure 3c). Primers designed from the Pc123 vcp1 gene sequence could amplify the gene from other Pc strains apart from that of Pc123 (Figure S5.) These strains were detected in banana roots $30 \mathrm{dpi}$. As seen in Figure 3d, there was root colonization by Pc strains.

(a)

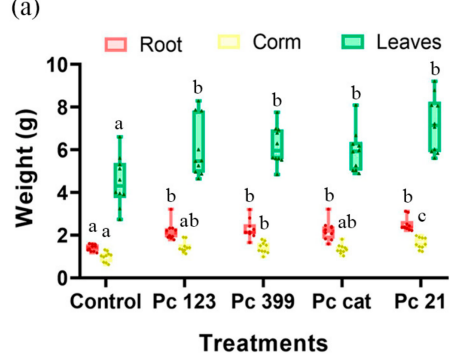

(b)

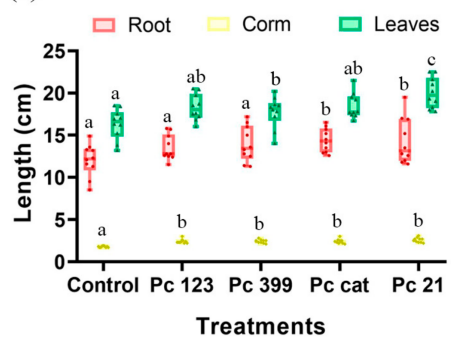

(c)

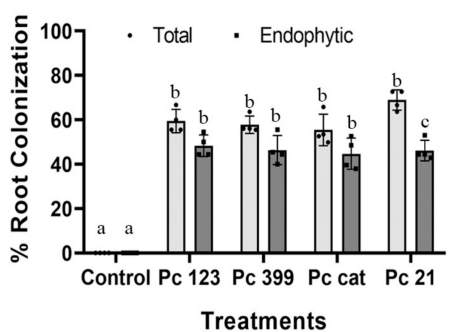

(d)

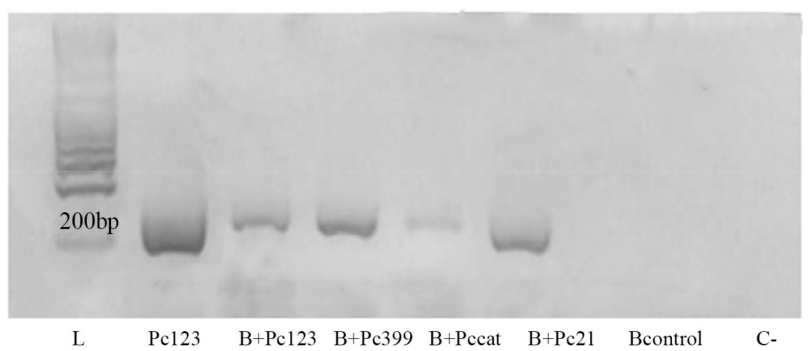

Figure 3. Effect of P. chlamydosporia diversity on the growth of 30-day-old plantlets. Treatments: inoculation of $5 \times 10^{4}$ conidia and chlamydospores suspension of each Pc strains (Pc123, Pc399, Pccat, and Pc21). (a) Root, corm, and leaf corm weight. (b) Fresh root, corm, and leaf length. (c) Total and endophytic root colonization. Growth indicators analyzed individually, the treatments with different letters show significant differences ( $p$-value $<\alpha=0.05$ ), treatments without letters indicate there are no significant differences. (d) Molecular detection of Pc strains colonizing M. acuminata roots, using the vpc1 gene. Abbreviations: L, ladder; B+Pc123, B+Pc399, B+Pc cat, B+Pc21, DNA extracted from 30 dpi roots of banana plant with different strains of Pc; Bcontrol, DNA extracted from 30-day-old plant (M. acuminata) roots without Pc; C-, negative control without DNA.

\section{Discussion}

The banana crop is essential for food security and therefore it is the most consumed and cultivated fruit in tropical and subtropical countries [38]. In view of the burst of human population in the last 50 years, the increase in food production requires improvement of crop management [3]. Traditionally chemical control has been used to enhance banana yield worldwide. Phytochemicals can infiltrate in water and this has been associated with human chronic neurobehavioral dysfunctions $[39,40]$. To reduce these impacts, sustainable practices for banana crop protection should be investigated [41].

Wild banana plants are colonized by a wide diversity of root endophytes [42]. The nematophagous fungus Pc has recently been found as a natural component of the banana rhizosphere in Canary Islands (Spain) [43]. This fungus has been found as an endophyte in several crops promoting their development [23-25]. In this paper, we propose the use of Pc as endophytic biological control agent (EBCA) in banana plants to improve crop yield. The use of biological control agents, mainly fungi, could be an alternative to the application of chemicals for banana crops management. Some fungi like Pc or Trichoderma are widely used in other important crops such as soybean or tomato plants to promote growth and for plant defense induction [44,45]. 
Our study establishes the basis for an optimal Pc inoculation methodology in banana plants. We found that spore suspensions are better inoculants than mycelia treatments, both in growth chambers and greenhouse experiments. Moreover, the use of conidia and chlamydospores in a water suspension means that the solution could be included directly in the irrigation system, avoiding unnecessary costs.

In our investigation, we demonstrated that Pc significantly increases root and leaf length and leaf weight in 30-day-old banana plantlets. Therefore, Pc can be inoculated at different phenological stages of the plant, enhancing plant growth and yield. This fact supports our results in the greenhouse, in which we observed that monthly applications of Pc spores increase leaf weight and root, pseudostem, and leaf length in 105-day-old banana plants. Similar results have been found in another important crop such as pea, where Pc inoculation during the seed stage, also provides root growth promotion [46]. Pc can also promote plant growth even in RKN infected banana roots [47] or in combination with other biological control agents such as the trapping fungus Duddingtonia flagrans [25].

We observed that banana plant growth promotion by Pc is strain dependent. Previous results showed a strain-dependent tomato growth and yield promotion by Pc. The inoculation of this fungus in tomato plants also reduces flowering and fruiting time [27]. In our work, we found that Pc21 from Italy is the most efficient growth promoter Pc strain on banana plants. Besides, the other Pc strains (Pc123, Pc399, and Pccat) also increase root and weight and corm length. Previous work described that Pccat chlamydospores based product $\left(\mathrm{Klamic}^{\circledR}\right)$ was used to inoculate banana in vitro plant AAB and AAAB cultivars [48]. These authors found, as in our study with AAA banana, growth promotion by P. chlamydosporia var. catenulata (Pccat) strain. The growth promotion generated by Pc could be related to its ability to induce the IAA biosynthesis pathway or by enhancing the nutrient uptake [25]. Similar studies with growth-promoting endophytic rhizobacteria found that Bacillus and Pseudomonas can also induce IAA. This phytohormone is directly involved in root development and cellular division, ultimately promoting plant growth [29].

Using a root culturing technique [33] we found endophytic colonization of banana roots by Pc. This fungus has been detected colonizing endophytically other plant roots, such as barley, corn, and pepper $[30,49,50]$. By using the $v c p 1$ gene target, encoding a serine protease, we detected Pc colonizing banana roots endophytically. This gene has been used in previous studies to detect and quantify Pc in the rhizosphere of important crops such as tomato or barley [27,34,51]. We observed that Pc21 is the best growth-promoting Pc strain and the best root colonizer. Although in other studies differences have been observed in rhizosphere competence by Pc strains in tomato which changed with plant age [27]. Differences in root colonization between Pc strains may be due to their abilities to modulate jasmonic acid (JA) plant response [21]. Similar behavior has also been studied on strains of the entomopathogenic fungus Metarrizhium spp. [50]. They also found Pc which was the best root colonizer with ca. 4-fold the rhizosphere competence of their best Metarhizium strain. This is perhaps connected with the evolutionary relatedness of both fungi [52,53]. The good rhizosphere competence of Pc in banana can be explained by the fact that Pc seems to prefer monocot to dicot plants [50]. The presence of Pc in roots or in the rhizosphere can exclude other fungal root colonizers by competence or biosynthesis of antimicrobial compounds $[30,54]$. Other studies found that by manipulating the banana rhizosphere microbiome it is possible to control the devastating fungus F. oxysporum f.sp. cubense tropical race 4 [55], the main current threat to banana plants. Pc as an endophyte could be an interesting EBCA not only to enhance banana plant growth also for managing F. oxysporum f.sp. cubense. Our study demonstrates that Pc colonizes the root system and promotes growth in M. acuminata plants. These results will establish the basis of Pc as a biofertilizer and bioprotectant of banana to biotic and abiotic stresses.

\section{Conclusions}

In this work the following conclusions were obtained: we observed that conidia and chlamydospores are better inoculants than mycelia. In greenhouse conditions conidia and chlamydospores re-inoculations promote the banana growth more than a single dose, but we can detect the fungus at 30 and 75 days post 
inoculation in banana roots, so the fungus persists in the rhizosphere for a long time. There is variability in the growth promotion and root colonization by the different $P$. chlamydosporia strains.

Supplementary Materials: The following are available online at http://www.mdpi.com/2073-4395/10/9/1299/s1, Figure S1. P. chlamydosporia effect on the number of leaves per 30-day-old banana plant. Figure S2. Effect of P. chlamydosporia 123 on the number of leaves per 105-day-old banana plant. Figure S3. Standard curve for real-time PCR of 4-fold serial dilutions of DNA from P. chlamydosporia. Figure S4. Effect of P. chlamydosporia diversity on the number of leaves per plant. Figure S5. Molecular detection of P. chlamydosporia strains.

Author Contributions: Investigation, methodology, formal analysis, writing (original draft), and visualization, C.M.-U.; supervision, methodology and reviewing, F.L.-M.; supervision, methodology, writing (original draft), reviewing, and funding acquisition, L.V.L.-L. All authors have read and agreed to the published version of the manuscript.

Funding: This research was funded by EU H2020, Musa Project (727624).

Acknowledgments: We thank members of the Laboratory of Plant Pathology (University of Alicante) for their help in greenhouse experiments.

Conflicts of Interest: The authors declare that they do not have any commercial or associative interest that represents a conflict of interest in connection with the work submitted. The funders had no role in the design of the study; in the collection, analyses, or interpretation of data; in the writing of the manuscript, or in the decision to publish the results.

\section{References}

1. Gold, C.S.; Pena, J.E.; Karamura, E.B. Biology and Integrated Pest Management for the Banana Weevil Cosmopolites sordidus (Germar) (Coleoptera: Curculionidae). Integr. Pest Manag. Rev. 2001, 6, 79-155. [CrossRef]

2. Perrier, X.; De Langhe, E.; Donohue, M.; Lentfer, C.; Vrydaghs, L.; Bakry, F.; Carreel, F.; Hippolyte, I.; Horry, J.-P.; Jenny, C.; et al. Multidisciplinary Perspectives on Banana (Musa spp.) Domestication. Proc. Natl. Acad. Sci. USA 2011, 108, 11311-11318. [CrossRef] [PubMed]

3. Pingali, P.L. Green Revolution: Impacts, Limits, And the Path Ahead. Proc. Natl. Acad. Sci. USA 2012, 109, 12302-12308. [CrossRef] [PubMed]

4. Shekhawat, U.K.S.; Ganapathi, T.R. MusaWRKY71 Overexpression in Banana Plants Leads to Altered Abiotic and Biotic Stress Responses. PLoS ONE 2013, 8, e75506. [CrossRef]

5. Gang, G.; Bizun, W.; Weihong, M.; Xiaofen, L.; Xiaolin, Y.; Chaohua, Z.; Jianhong, M.; Huicai, Z. Biocontrol of Fusarium Wilt of Banana: Key Influence Factors and Strategies. Afr. J. Microbiol. Res. 2013, 7, 4835-4843.

6. Dubois, T.; Gold, C.S.; Coyne, D.; Paparu, P.; Mukwaba, E.; Athman, S.; Kapinduand, S.; Adipala, E. Merging Biotechnology with Biological Control: Banana Musa Tissue Culture Plants Enhanced by Endophytic Fungi. Uganda J. Agric. Sci. 2004, 9, 445-451.

7. Khanal, C.; Desaeger, J.A. On-Farm Evaluations of Non-Fumigant Nematicides on Cucurbits. Crop. Prot. 2020, 133, 105152. [CrossRef]

8. Li, J.; Meng, Z.; Li, N.; Dong, B.; Ji, X.; Zhang, S.; Qiao, K. Evaluating a New Non-Fumigant Nematicide Fluopimomide for Management of Southern Root-Knot Nematodes in Tomato. Crop. Prot. 2020, 129, 105040. [CrossRef]

9. Wu, K.; Chen, W.; Yang, S.; Wen, Y.; Zheng, Y.; Anjago, W.M.; Yun, Y.; Wang, Z. Isolation and Identification of Fusarium oxysporum f. Sp. Cubense in Fujian Province, China. J. Integr. Agric. 2019, 18, 1905-1913. [CrossRef]

10. Davies, L.J.; Elling, A.A. Resistance genes against plant-parasitic nematodes: A durable control strategy? Nematology 2015, 17, 249-263. [CrossRef]

11. Dos Santos, M.C.V.; Abrantes, I.; Curtis, R.H. Priming Plant Defence Responses Can Enhance the Biological Control of Pochonia Chlamydosporia Against Root-Knot Nematodes. In Perspectives in Sustainable Nematode Management through Pochonia chlamydosporia Applications for Root and Rhizosphere Health; Springer: Berlin/Heidelberg, Germany, 2017; pp. 295-309.

12. Manzanilla-López, R.H.; Esteves, I.; Finetti-Sialer, M.M.; Hirsch, P.R.; Ward, E.; Devonshire, J.; Hidalgo-Díaz, L. Pochonia chlamydosporia: Advances and Challenges to Improve Its Performance as a Biological Control Agent of Sedentary Endo-Parasitic Nematodes. J. Nematol. 2013, 45, 1-7.

13. Escudero, N.; Ferreira, S.R.; Lopez-Moya, F.; Naranjo-Ortiz, M.A.; Marin-Ortiz, A.I.; Thornton, C.R.; Lopez-Llorca, L.V. Chitosan Enhances Parasitism of Meloidogyne javanica Eggs by the Nematophagous Fungus Pochonia chlamydosporia. Fungal Biol. 2016, 120, 572-585. [CrossRef] [PubMed] 
14. Gams, W.; Zare, R. A Revision of Verticillium Sect. Prostrata. III. Generic Classification. Nova Hedwig. 2001, 72, 329-337. [CrossRef]

15. Giné, A.; Bonmatí, M.; Sarro, A.; Stchiegel, A.; Valero, J.; Ornat, C.; Fernández, C.; Sorribas, F.J. Natural Occurrence of Fungal Egg Parasites of Root-Knot Nematodes, Meloidogyne spp. in Organic and Integrated Vegetable Production Systems in Spain. BioControl 2013, 58, 407-416. [CrossRef]

16. Kerry, B.; Esteves, I.; Dos Santos, M.C.V.; Abrantes, I. Biology, Growth Parameters and Enzymatic Activity of Pochonia chlamydosporia Isolated from Potato Cyst and Root-Knot Nematodes. Nematology 2013, 15, 493-504. [CrossRef]

17. Viggiano, J.R.; de Freitas, L.G.; Lopes, E.A. Use of Pochonia chlamydosporia to Control Meloidogyne javanica in Cucumber. Biol. Control 2014, 69, 72-77. [CrossRef]

18. Ward, E.; Kerry, B.R.; Manzanilla-López, R.H.; Mutua, G.; Devonshire, J.; Kimenju, J.; Hirsch, P.R. The Pochonia chlamydosporia Serine Protease Gene Vcp1 Is Subject to Regulation by Carbon, Nitrogen and PH: Implications for Nematode Biocontrol. PLOS ONE 2012, 7, e35657. [CrossRef]

19. Escudero, N.; Marhuenda-Egea, F.C.; Ibanco-Cañete, R.; Zavala-Gonzalez, E.A.; Lopez-Llorca, L.V. A Metabolomic Approach to Study the Rhizodeposition in the Tritrophic Interaction: Tomato, Pochonia chlamydosporia and Meloidogyne javanica. Metabolomics 2014, 10, 788-804. [CrossRef]

20. Bordallo, J.J.; Lopez-Llorca, L.V.; Jansson, H.-B.; Salinas, J.; Persmark, L.; Asensio, L. Colonization of Plant Roots by Egg-Parasitic and Nematode-Trapping Fungi. New Phytol. 2002, 154, 491-499. [CrossRef]

21. Zavala-Gonzalez, E.A.; Rodríguez-Cazorla, E.; Escudero, N.; Aranda-Martinez, A.; Martínez-Laborda, A.; Ramírez-Lepe, M.; Vera, A.; Lopez-Llorca, L.V. Arabidopsis thaliana Root Colonization by the Nematophagous Fungus Pochonia chlamydosporia Is Modulated by Jasmonate Signaling and Leads to Accelerated Flowering and Improved Yield. New Phytol. 2017, 213, 351-364. [CrossRef]

22. Cheng, C.; Li, D.; Qi, Q.; Sun, X.; Anue, M.R.; David, B.M.; Zhang, Y.; Hao, X.; Zhang, Z.; Lai, Z. The Root Endophytic Fungus Serendipita Indica Improves Resistance of Banana to Fusarium oxysporum $\mathrm{f}$. Sp. Cubense Tropical Race 4. Eur. J. Plant Pathol. 2020, 156, 87-100. [CrossRef]

23. Monfort, E.; Lopez-Llorca, L.V.; Jansson, H.-B.; Salinas, J.; Park, J.O.; Sivasithamparam, K. Colonisation of Seminal Roots of Wheat and Barley by Egg-Parasitic Nematophagous Fungi and Their Effects on Gaeumannomyces graminis Var. Tritici and Development of Root-Rot. Soil Biol. Biochem. 2005, 37, 1229-1235. [CrossRef]

24. Dallemole-Giaretta, R.; Freitas, L.G.; Lopes, E.A.; Silva, M.D.C.S.D.; Kasuya, M.C.M.; Ferraz, S. Pochonia chlamydosporia promotes the growth of tomato and lettuce plants. Acta Sci. Agron. 2015, 37, 417-423. [CrossRef]

25. Monteiro, T.S.A.; Valadares, S.V.; de Mello, I.N.K.; Moreira, B.C.; Kasuya, M.C.M.; de Araújo, J.V.; de Freitas, L.G. Nematophagus Fungi Increasing Phosphorus Uptake and Promoting Plant Growth. Biol. Control 2018, 123, 71-75. [CrossRef]

26. Tsavkelova, E.A.; Klimova, S.Y.; Cherdyntseva, T.A.; Netrusov, A.I. Microbial producers of plant growth stimulators and their practical use: A review. Appl. Biochem. Microbiol. 2006, 42, 117-126. [CrossRef]

27. Zavala-Gonzalez, E.A.; Escudero, N.; Lopez-Moya, F.; Aranda-Martinez, A.; Exposito, A.; Ricaño-Rodríguez, J.; Naranjo-Ortiz, M.A.; Ramírez-Lepe, M.; Lopez-Llorca, L.V. Some Isolates of the Nematophagous Fungus Pochonia chlamydosporia Promote Root Growth and Reduce Flowering Time of Tomato. Ann. Appl. Biol. 2015, 166, 472-483. [CrossRef]

28. Larriba, E.; Jaime, M.D.L.A.; Nislow, C.; Martín-Nieto, J.; Lopez-Llorca, L.V. Endophytic Colonization of Barley (Hordeum vulgare) Roots by the Nematophagous Fungus Pochonia chlamydosporia Reveals Plant Growth Promotion and a General Defense and Stress Transcriptomic Response. J. Plant Res. 2015, 128, 665-678. [CrossRef]

29. Dadrasnia, A.; Usman, M.M.; Omar, R.; Ismail, S.; Abdullah, R. Potential Use of Bacillus Genus to Control of Bananas Diseases: Approaches toward High Yield Production and Sustainable Management. J. King Saud Univ.-Sci. 2020, 32, 2336-2342. [CrossRef]

30. Maclá-Vicente, J.G.; Rosso, L.C.; Ciancio, A.; Jansson, H.B.; Lopez-Llorca, L.V. Colonisation of Barley Roots by Endophytic Fusarium equiseti and Pochonia chlamydosporia: Effects on Plant Growth and Disease. Ann. Appl. Biol. 2009, 155, 391-401. [CrossRef]

31. Olivares-Bernabeu, C.M.; López-Llorca, L.V. Fungal Egg-Parasites of Plant-Parasitic Nematodes from Spanish Soils. Rev. Iberoam. Micol. 2002, 19, 104-110. 
32. Maciá-Vicente, J.G.; Ferraro, V.; Burruano, S.; Lopez-Llorca, L.V. Fungal Assemblages Associated with Roots of Halophytic and Non-Halophytic Plant Species Vary Differentially Along a Salinity Gradient. Microb. Ecol. 2012, 64, 668-679. [CrossRef] [PubMed]

33. Lopez-Llorca, L.V.; Duncan, J.M. New Media for the Estimation of Fungal Infection in Eggs of the Cereal Cyst Nematode, Heterodera avenae Woll. Nematologica 1986, 32, 486-489. [CrossRef]

34. Escudero, N.; Lopez-Llorca, L.V. Effects on Plant Growth and Root-Knot Nematode Infection of an Endophytic GFP Transformant of the Nematophagous Fungus Pochonia chlamydosporia. Symbiosis 2012, 57, 33-42. [CrossRef]

35. O'Donnell, K.; Cigelnik, E.; Nirenberg, H.I. Molecular Systematics and Phylogeography of the Gibberella Fujikuroi Species Complex. Mycologia 1998, 90, 465-493. [CrossRef]

36. Lopez-Llorca, L.V.; Gómez-Vidal, S.; Monfort, E.; Larriba, E.; Casado-Vela, J.; Elortza, F.; Jansson, H.B.; Salinas, J.; Martín-Nieto, J. Expression of Serine Proteases in Egg-Parasitic Nematophagous Fungi during Barley Root Colonization. Fungal Genet. Biol. 2010, 47, 342-351. [CrossRef]

37. Maciá-Vicente, J.G.; Jansson, H.-B.; Talbot, N.J.; Lopez-Llorca, L.V. Real-Time PCR Quantification and Live-Cell Imaging of Endophytic Colonization of Barley (Hordeum vulgare) Roots by Fusarium equiseti and Pochonia chlamydosporia. New Phytol. 2009, 182, 213-228. [CrossRef] [PubMed]

38. Ferri, D.V.; Munhoz, C.F.; Neves, P.M.O.; Ferracin, L.M.; Sartori, D.; Vieira, M.L.C.; Fungaro, M.H.P. Genetic Variability of Beauveria bassiana and a DNA Marker for Environmental Monitoring of a Highly Virulent Isolate Against Cosmopolites sordidus. Indian J. Microbiol. 2012, 52, 569-574. [CrossRef]

39. Wesseling, C.; Keifer, M.; Ahlbom, A.; McConnell, R.; Moon, J.-D.; Rosenstock, L.; Hogstedt, C. Long-Term Neurobehavioral Effects of Mild Poisonings with Organophosphate and n-Methyl Carbamate Pesticides among Banana Workers. Int. J. Occup. Environ. Health 2002, 8, 27-34. [CrossRef]

40. Diepens, N.J.; Pfennig, S.; Brink, P.J.V.D.; Gunnarsson, J.S.; Ruepert, C.; Castillo, L.E. Effect of Pesticides Used in Banana and Pineapple Plantations on Aquatic Ecosystems in Costa Rica. J. Environ. Biol. 2014, 35, 73-84.

41. Vézina, A.; Van den Bergh, I. Pesticide-Redicing Practices. Available online: http://www.promusa.org/ Pesticidereducing+practices+ portal (accessed on 15 March 2020).

42. Life, T. Short Communication: Molecular Characterisation of Endophytic Fungi from Roots of Wild Banana. Trop. Life Sci. Res. 2016, 27, 153-162.

43. Ciancio, A.; Colagiero, M.; Rosso, L.; Pentimone, I.; Cepero, J.L. A Metagenomic Study of Banana Nematode Antagonists in Canary Island. Nematropica 2020, 49.

44. Chakraborty, B.N.; Chakraborty, U.; Sunar, K. Induced Immunity Developed by Trichoderma Species in Plants. In Trichoderma: Host Pathogen Interactions and Applications; Springer: Singapore, 2020; pp. 125-147. [CrossRef]

45. Vinale, F.; Sivasithamparam, K. Beneficial effects of Trichoderma secondary metabolites on crops. Phytother. Res. 2020. [CrossRef] [PubMed]

46. Ortega, J.A.; Socorro, M.Á.H.; Piedra, A.L.; de Martínez, N.M.O.; Hidalgo-Díaz, L. Efecto de Pochonia chlamydosporia Var. Catenulata (Goddard) Zare y Gams Como Endófito Facultativo En Frijol (Phaseolus vulgaris L.). Rev. Prot. Veg. 2019, 34.

47. Barbosa, R.T.; Monteiro, T.S.A.; Coutinho, R.R.; Silva, J.G.; Freitas, L.G.; Gerais, M.; Gerais, M.; Monteiro, T.S.A.; Coutinho, R.R.; Silva, J.G. Pochonia chlamydosporia No Controle. Nematropica 2019, 49, 99-106.

48. Hernández-Socorro, M.A.; Arévalo-Ortega, J.; Marrero-Roque, D.; Hidalgo-Díaz, L. Efecto de KlamiC ${ }^{\circledR}$ En La Estimulación Del Crecimiento de Vitroplantas de Plátanos y Bananos. Cultiv. Trop. 2016, 37, 168-172.

49. Maciá-Vicente, J.G.; Jansson, H.B.; Mendgen, K.; Lopez-Llorca, L.V. Colonization of Barley Roots by Endophytic Fungi and Their Reduction of Take-All Caused by Gaeumannomyces graminis Var. Tritici. Can. J. Microbiol. 2008, 54, 600-609. [CrossRef]

50. Moonjely, S.; Bidochka, M.J. Generalist and Specialist Metarhizium Insect Pathogens Retain Ancestral Ability to Colonize Plant Roots. Fungal Ecol. 2019, 41, 209-217. [CrossRef]

51. Ghahremani, Z.; Escudero, N.; Saus, E.; Gabaldón, T.; Sorribas, F.J. Pochonia chlamydosporia Induces Plant-Dependent Systemic Resistance to Meloidogyne incognita. Front. Plant Sci. 2019, 10, 945. [CrossRef]

52. Larriba, E.; Jaime, M.D.L.A.; Carbonell-Caballero, J.; Conesa, A.; Dopazo, J.; Nislow, C.; Martín-Nieto, J.; Lopez-Llorca, L.V. Sequencing and Functional Analysis of the Genome of a Nematode Egg-Parasitic Fungus, Pochonia chlamydosporia. Fungal Genet. Biol. 2014, 65, 69-80. [CrossRef]

53. Lin, R.; Qin, F.; Shen, B.; Shi, Q.; Liu, C.; Zhang, X.; Jiao, Y.; Lu, J.; Gao, Y.; Suarez-Fernandez, M.; et al. Genome and Secretome Analysis of Pochonia chlamydosporia Provide New Insight into Egg-Parasitic Mechanisms. Sci. Rep. 2018, 8, 1123. [CrossRef] 
54. Nandhini, M.; Rajini, S.; Udayashankar, A.; Niranjana, S.; Lund, O.S.; Shetty, H.S.; Prakash, H.S. Diversity, plant growth promoting and downy mildew disease suppression potential of cultivable endophytic fungal communities associated with pearl millet. Biol. Control. 2018, 127, 127-138. [CrossRef]

55. Xue, C.; Penton, C.R.; Shen, Z.; Zhang, R.; Huang, Q.; Li, R.; Ruan, Y.; Shen, Q. Manipulating the banana rhizosphere microbiome for biological control of Panama disease. Sci. Rep. 2015, 5, 11124. [CrossRef] [PubMed]

(C) 2020 by the authors. Licensee MDPI, Basel, Switzerland. This article is an open access article distributed under the terms and conditions of the Creative Commons Attribution (CC BY) license (http://creativecommons.org/licenses/by/4.0/). 